\title{
Socioeconomic and Cost - Effective on Deforestation Compliancy Policies as Oppose to Pure Deterrence Model of Regulatory Compliance
}

\author{
Akintola Ismail, PhD \\ Department of Sociology and Anthropology \\ Faculty of Business and Social Sciences, Baze University, Nigeria \\ Bushi Kasimu Musa, (M.SC./MBA) \\ Independent Researcher And Consultant \\ Sule Magaji, Professor \\ Economics Department, University of Abuja, Nigeria
}

Doi:10.19044/esj.2019.v15n28p253 URL:http://dx.doi.org/10.19044/esj.2019.v15n28p253

\begin{abstract}
This paper analyzes the causes of regulatory compliance using traditional deterrence variables and potential moral and social variables. Selfreported data was used to assert the objective of this write-up. A group of persistent violators react neither to normative aspects nor to traditional deterrence variables, but systematically violate the regulation and use bribes to avoid punishment. From the results, it was also indicated that tree hunters adjust their violation rates with respect to changes in the probability of detection and punishment, but they also react to social and legitimacy variables. It is recommended that if the on-going deforestation, forest depletion and degradation are to be curbed, it is essential to have proactive and forward-looking policies anticipating social, economic and environmental changes to guide the development of the forest sector. Social influence plays a significant role in everyday social exchange-the body of empirical evidence demonstrates that the pure deterrence model of regulatory compliance, which focuses primarily on the certainty and severity of sanctions as key determinants of compliance, provides a partial explanation of compliance behaviour.
\end{abstract}

Keywords: Socio-economic activities self-enforcement, Legitimacy, Normative, Enforcement strategies, Deterrence, Regulation, Compliance, Regulatory cooperation, Degradation, Deforestation 


\section{Introduction}

Natural resource industries, because of the prevalence of externalities and public goods, inevitably become highly regulated. Even where a full set of property rights is defined to internalize externalities, it is necessary to control excluded users from infringing on those rights. Other industries where market structure or public safety and security are potential problems also are subject to an array of government restrictions.

Regulated economic agents are typically controlled through monitoring, surveillance, and enforcement. This control is commonly left to separate enforcement authorities and not systematically considered when developing regulatory policies. There is little or no recognition of how policies and the policy process may affect the extent of compliance with regulations (Kupera. and Sutinen, 1994). Policy analysis and formulation frequently assume perfect compliance can be achieved at no cost. Yet, when things go wrong, as they often do, enforcement is cited as one of the principal reasons for failure, and more and better enforcement is demanded. This raises questions of whether there are ways to improve the cost-effectiveness of traditional enforcement, and whether there are ways to secure compliance without heavy reliance on costly enforcement.

Prescribing compliance policy and institutional design requires a sound understanding of compliance behavior. Becker (1968) was the first to develop a formal theoretical framework for explaining criminal activity. Following Bentham (1789) and Smith (1759, 1776), Becker argued that criminals behave basically like other individuals in that they attempt to maximize utility subject to a budget constraint. In Becker's model, an individual commits a crime if the expected utility from committing the crime exceeds the utility from engaging in legitimate activity. Becker's framework became the launching pad for a series of studies on the economics of crime. The original deterrence model by Becker (1968) led to a large number of empirical papers testing the hypothesis (starting with Erlich, 1973; Gaviria, 2000 is a recent extension), which by and large confirmed the theory. Whether the deterrence conclusion is confirmed has been debated, however, and one level of critique is methodological. This critique stresses that the theory is developed on the individual level, while much of the empirical work is based on some level of aggregation. If crime rate is defined as crime per capita, and probability to be arrested is measured as the ratio of arrests to crimes, we have the number of crimes in the denominator of the independent variable and in the numerator of the dependent variable, which can imply spurious correlation. Similarly, if notorious criminals are arrested and kept in custody, it implies a lower crime level, but the negative correlation between crime and arrest rates is not due to the risk of being arrested, but to the actual captivity. 
More crimes lead to more expenditure on law enforcement, which implies a simultaneous relationship between crime and enforcement levels. Manski (1978) suggested survey-collected individual self-reports as a means of avoiding these problems, since each individual will have a negligible impact on each of the three objections raised. Furlong (1991) applied these ideas to Canadian fishers and found the fishers to be most sensitive to changes in the likelihood of detection, while fines appeared to create the greatest deterrence among various penalties.

Social science research on why people follow the law has been dominated by the instrumental perspective, which is based on deterrence literature and reaches the same policy conclusions as the economics research following the Becker approach. However, given the weak deterrent threat facing people for minor violations, this approach cannot explain why the vast majority of people act in a way consistent with the law (Robinson and Darley, 1997). Recent contributions to legal thought, which to a large extent are revivals of older ideas, provide several suggestions. One reason for following the rules is to avoid the disapproval of your social group; another is that you see yourself as a moral being who wants to do the right thing (Robinson and Darley, 1997). A third factor is legitimacy, which means that the individual feels that the authority enforcing the law is entitled to dictate behavior. This in turn depends on whether individuals think that the law is fair and applied in a fair manner. Whether legitimacy is maintained or undermined is dependent on people's experiences with legal authorities (Tyler 1990).

Enforcement in natural resource industry(ies) has been a fairly neglected area (Sutinen and Hennessey, 1986). The early contributions are theoretical and deal with optimal stock if non-zero enforcement costs are introduced (Sutinen and Andersen, 1985; Milliman, 1986) and the choice of optimal government policy (Anderson and Lee, 1986). The first empirical study confirmed the deterrence model showing that an increased risk of detection and conviction reduce the violation rate in Natural resource industries (Sutinen and Gauvin, 1989). The simple deterrence model predicts that most fishers will violate the regulation. The risk of detection is low, fines are modest, and the profits from violation are substantial. Extended analysis is therefore necessary to include both the instrumental and the normative perspective. The empirical evidence from such an approach is mixed. Kuperan and Sutinen (1998) found that compliance in a Malaysian fishery depended on the tangible gains and losses, as well as the moral development, legitimacy, and behavior of others.

Hatcher et al. (2000) reached similar conclusions while Hatcher and Gordon (2005) found less evidence in favor of normative influence on fisher compliance, while again confirming the deterrence effect. Specifically, the model accounts for moral obligation and social influence in addition to the 
conventional costs and revenues associated with illegal behavior. The model integrates sociology, economic and psychology theories to account for both tangible and intangible motivations influencing individuals' decisions whether to comply with a given set of regulations. This paper analyzes the causes of regulatory compliance In addition to traditional deterrence variables such as risk of detection and expected gains from violation, we explore potential reasons for following the rules such as being moral and doing the right thing, obeying the rules due to peer pressure from other loggers, perceiving the regulation as legitimate, and perceiving that they (Feller) have been involved in the regulation process. We use self-reported data from Osun South-Western Nigeria because the forest reserves are under severe illegal exploitation and focus on analysis forestry sub-sector regulation.

\section{Conceptual Clarifications: Deforestation}

Deforestation is a process whereby trees are felled for several purposes but without replanting to replace the ones felled (Aina and Salau, 1992). It is the large scale removal of forests resulting to non forest areas for urbanization, agriculture and for some other reasons without corresponding re-afforestation of the area (Fiset, 2011). According to FAO (2005), deforestation is the conversion of forest to another land use or the long term-term reduction of tree canopy cover below the $10 \%$ threshold. On a broad sense, deforestation can apart from conversion of forest areas to non-forest ones, include reduction of forest quality in terms of its density, structure of the trees, the ecological and other essential services supplied, biota biomass and species diversity as well as the genetic diversity of the composing biota.

Deforestation is a major problem in many parts of the world, and the idea underlying the phenomenon can be a diminution of vegetal covers from thick forest to light forest, from heavy or light forest to open area under development. It can also be from heavy or light forest to savannah or grassland and or from savannah to open or isolated land (Okorie, 2012).

In spite of the multi-various usefulness of the forest resources, rapid population growth and changes in land uses have put the forest resources under pressure. For instance, majority of logging operations in tropical countries are considered unsuitable and damaging. The widespread failure of forest governance - characterized by illegal logging, associated illegal trade, and corruption-directly undermines sustainable economic growth, equitable development, and environmental conservation. It puts at risk poor and forestdependent populations, which rely on timber and non-timber forest products; undermines responsible forest enterprises by distorting timber and reducing profitability; and results in a loss of government revenue that could be invested 
in sustainable forest management or general economic development (World Bank, 2006).

\section{Forest degradation}

Forest degradation is a process leading to a temporary or permanent deterioration in the density or structure of vegetation cover or its species composition (FAO, 2007). It results from disturbances that cause changes in the forest attributes that leads to a reduced productive capacity of the forest. For the purpose of having a harmonized set of forest and forest change definitions, that also is measurable with conventional techniques, forest degradation is assumed to be indicated by the reduction of canopy cover and/or stocking of the forest through logging, canopy cover stays above $10 \%$ (Olagunju, 2015). In a more general sense, forest degradation is the long-term reduction of the overall potential supply of benefits from the forest, which includes wood, biodiversity and any other product or service.

\section{Forest fragmentation}

Forest fragmentation is any process that converts once a continuous forest area into fragments or patches of forest separated by non-forest lands. Fragmentation is a complex phenomenon resulting from dynamic interactions between the natural landscape and society's ever-increasing demands on the land, creating a mosaic of natural and human modified environments (FAO, 2007). Forest fragmentation is basically the conversion of large areas of contiguous native forest to other types of vegetation and /or land use leaving remnant patches of forest that varies in size and isolation.

\section{Statement of the problem}

Illegal felling and poaching are twin evils affecting resources management in the forestry sub-sector. The forest reserves and wildlife sanctuaries are under severe illegal exploitation. Ajakaiye (2001) reported that in the last years of military, there was collusion with foreigners in felling of teak trees across most plantations established in the country in the 1950s and 1960. Illegal logging may generate employment in the short term but in the longer term it can contribute to the depletion of timber resources and the subsequent collapse of forest industries. Every year developing country governments lose billions of dollars in revenues due to illegal tax evasion in the forestry sector and unauthorized timber harvesting in public owned forest (FAO, 2001). Seyer ( 2005) reported that when local people complain about illegal forestry activities, the implicated parties often respond with threats or even violence. In addition the corrupt government officials sometimes take action against local people to pro-tect their interests or those of illegal loggers and poachers. Illegal forestry activities cause environmental damage and 
threatens forests which many people depend on. Though many tropical countries in Africa, Asia and Latin America rely on logging for exports earnings, illegal logging costs forest country governments at least US \$ $10-$ 15 billion a year - an amount greater than total World Bank lending to client countries and greater than total annual development assistance in public education and health (White and Martin,2002). According to Baird (2001), illegal logging costs Indonesia approximately US \$ 60 million annually, while Richards, Gatto and Lopez (2003) reported that the direct financial losses to the government of Hordurasand Nicaragua due to clandestine logging have been estimated at US \$11-18 mil-lion and US \$ 4-8million, respectively. It is also important to remember that illegal logging is not confined to the developing countries. The Russian Federation is a major timber producer and exports, and estimates of the extent of illegal logging range from $20-30$ percent of the country as a whole, to around 40-50 percent in particular areas of Siberia (Brack,Gray and Hayman, 2002,).According Faleyimu and Agbeja ineffective supervision, coordination and control is a major problem for forest policy implementation in the southwest except in Lagos and Ogun State. The long term fortunes of forestry depends largely on the institutions in place as well as the performance of the managers (Adeyoju, 2001;Adeyoju,2005). It means that irrespective of the sustain-ability strategy and the enabling environment, the human role is indispensable. Also accountability and transparency are important component of effective supervision coordination and control. The study revealed that inadequate information from policy makers is a problem of forest policy implementation. The over whelming influence and impact of communication and information for the smooth running of business has been acknowledge (CTA, 1997). Such information should not be only technically focused but should include economic data, policy Statement and regulations guiding the use of such resources. These industries and timber trade are important because they engaged many people in the lower income groups. According to Areola (1991), estimates of people engaged in different types of forestry activities were 170,000 in 1933, it increased to 360,000 in 1947 and to 586,000 in 1966 by 1983 it jumped to over $1,000,000$ the figure must be much more higher than that now.

Exploitation of forest resources often causes deforestation, which has been a big problem in this Nation. Nigeria destroys 600,00ha of forest annually whereas only 25,000ha are replenished (FAO, 1983). This is often done to service wood base industries apart from fuel. However, a huge sum of N180 Billion is lost annually to deforestation (Eboh, 2005). Deforestation has increased real fuel wood prices in the last two decades and this result in an estimated loss of between N45 to 60 billion annually. 
This economic cost of fuel wood losses per year was estimated by the increase in the cost of fuel wood supply taking into account, the increase in the cost of collecting the wood and the transportation costs. The lost of forest has also reduced access to and supplies of non-timber food products for export by as much as 40-50 percent in the last five years. This implies that in due course, Nigeria will depend on importation of wood and wood products, plunging the country into imbalance trade depleting the nation's foreign reserve.

\section{Description of Area of Study The Study Area}

The study area is Osun state. It is located in the Southwestern geopolitical zone. Osun State has an estimated population of 3,423,535(National Population Commission, 2006). The capital is Osogbo. The state which is made up of 30 local government council lies between longitude 40 and 60 east of the Greenwich Meridian, latitude 50 and 80- north of the equator. This means that the state lies entirely in the tropics. The state is bounded in the West by Oyo State, in the North by Kwara State, in the East by Ondo State and in the South by Ogun State. Agriculture is the traditional occupation of the people of Osun State. The tropical nature of the climate favours the growth of a variety of food and cash crops. The main cash crops include cocoa, palm produce, kola, while food crops include yam, maize, cassava, millet, rice and plantain. The vegetation consists of high forest and derived savannah towards the north. The climate is tropical with two distinct seasons. Usually the wet season last between March and October, while the dry season comes between November and February. Mean annual rainfall is between 2,000 and $2,2000 \mathrm{~mm}$. Maximum temperature is $32.50 \mathrm{C}$ while the relative humidity is 79.90percent. Osun state has been divided by OSSADEP into three agricultural zones and twenty five blocks (25) blocks. These are Osogbo (6 blocks), Ife/Ijesha (12 blocks) and Iwo ( 7 blocks). The study area was chosen because it was recognised as one of the major timber producing state with forest related environmental issues in the past and present (Agbeja, 2008).

\section{Data Collection}

Field survey, which entails detailed appraisal of the various aspects of the forest policy implementation, were carried out through the use of structured questionnaire containing both open and close ended questions and opinion/target group discussions to gather relevant data from forest stakeholders in Osun South-Western Nigeria.

\section{Population and Sample}

Primary data needed for the study were collected through multistage random sampling- where the study area is first stratified into zones, and each 
were further stratified into forestry administrative Zones: Ife, Ilesa, Ikirun,Osogbo, Iwo and Ede (FOMECU ,1998).

\section{Survey Description and Data}

The data for this study was collected using a questionnaire. The questionnaire was administered in face-to-face interviews with loggers with an assurance of individual anonymity and confidentiality. Consideration was taken in the design of the questionnaire to maximize the likelihood of honest responses, in particular regarding questions about the loggers' own violation behavior. The respondents were asked about their own violation rates during the last twelve-month period and gave answers such as "zero," "one month," "two to three months" or "twelve months," .Three subgroups were identified, which were labeled non-violators, alternating violators, and persistent violators, with zero, one to ten months, and eleven months or more of violation, respectively. Zero violation means that the respondent has not broken violations for the past twelve months; one month means that in the past twelve months he broke violations only one month, and so on. Interviews were carried out individually and included questions on respondent attitudes and perceptions about the legitimacy of loggers size regulation, social pressures to comply, attitudes towards violation and feelings of obligation to comply. The questionnaire design was to a large extent based on the questionnaire used by Kuperan and Sutinen (1998) and Håkan and Razack (2004) . Questions related to legitimacy concerned the perceived effectiveness and fairness of loggers size regulations, the legitimacy of management institutions, and the involvement of loggers in the management.

These questions were statements for which the respondents ranked their level of agreement on a four-digit scale, where a higher score means stronger agreement. Socioeconomic characteristics of the loggers were recorded either directly, (e.g., age and experience as a skipper, household size), or where appropriate, using an interval scale, e.g., household income was recorded in this way to minimize the concern of confidentiality and accuracy.

We also included questions related to the subjective probability of detection, arrest and conviction. Respondents were asked to report their own compliance behaviors as well as their perceptions of other loggers' compliance behavior at the same forest. Further, questions related to the level of loggers' involvement in policy formulation and enforcement were asked. Self-reports may imply a risk of biased data, especially as respondents were asked about their own illegal activities, but the overall impression was that the loggers were cooperative and generous with their answers, including their own violations.

Prescribing compliance policy and institutional design requires a sound understanding of compliance behavior. Becker (1968) was the first to 
develop a formal theoretical framework for explaining criminal activity. Following Bentham (1789) and Smith (1759, 1776), Becker argued that criminals behave basically like other individuals in that they attempt to maximize utility subject to a budget constraint. In Becker's model, an individual commits a crime if the expected utility from committing the crime exceeds the utility from engaging in legitimate activity. Becker's framework became the launching pad for a series of studies on the economics of crime (Heineke, 1978; Pyle 1983;Anderson and Lee, 1986 and Milliman, 1986).

The basic deterrence framework used in these studies assumes that the threat of sanctions is the only policy mechanism available to improve compliance with regulations. The basic deterrence model, however, has at least two important shortcomings: first, the model does not explain the available evidence very well and, second, the policy prescriptions of the model are not very practical. Low expected penalties do not always result in high levels of non-compliance; and prescriptions for more enforcement inputs and higher penalties are usually unfeasible or not cost-effective (Viswanathan,Sutinen and Kuperan, 1998). In an attempt to overcome these and other shortcomings, this paper presents an enriched model of compliance behavior as regard deforestation in which rational individuals are driven by both intrinsic and extrinsic motivations (including, but not restricted to, wealth enhancement). The model integrates sociology, economics and psychology theories to account for both tangible and intangible motivations influencing individuals' decisions whether to comply with a given set of regulations. Specifically, the model accounts for moral obligation and social influence in addition to the conventional costs and revenues associated with illegal behavior.

\section{Methodology}

The original deterrence model by Becker (1968) led to a large number of empirical papers testing the hypothesis (starting with Erlich, 1973; Gaviria, 2000 is a recent extension), which by and large confirmed the theory. Whether the deterrence conclusion is confirmed has been debated, however, and one level of critique is methodological. This critique stresses that the theory is developed on the individual level, while much of the empirical work is based on some level of aggregation. If crime rate is defined as crime per capita, and probability to be arrested is measured as the ratio of arrests to crimes, we have the number of crimes in the denominator of the independent variable and in the numerator of the dependent variable, which can imply spurious correlation. Similarly, if notorious criminals are arrested and kept in custody, it implies a lower crime level, but the negative correlation between crime and arrest rates is not due to the risk of being arrested, but to the actual captivity.

Finally, more crimes lead to more expenditures on law enforcement, which implies a simultaneous relationship between crime and enforcement 
levels. Manski (1978) suggested survey-collected individual self-reports as a means of avoiding these problems, since each individual will have a negligible impact on each of the three objections raised. Furlong (1991) applied these ideas to Canadian fishers and found the fishers to be most sensitive to changes in the likelihood of detection, while fines appeared to create the greatest deterrence among various penalties.

Social science research on why people follow the law has been dominated by the instrumental perspective, which is based on deterrence literature and reaches the same policy conclusions as the economics research following the Becker approach. However, given the weak deterrent threat facing people for minor violations, this approach cannot explain why the vast majority of people act in a way consistent with the law (Robinson and Darley, 1997). Recent contributions to legal thought, which to a large extent are revivals of older ideas, provide several suggestions. One reason for following the rules is to avoid the disapproval of your social group; another is that you see yourself as a moral being who wants to do the right thing (Robinson and Darley, 1997). A third factor is legitimacy, which means that the individual feels that the authority enforcing the law is entitled to dictate behavior. This in turn depends on whether individuals think that the law is fair and applied in a fair manner. Whether legitimacy is maintained or undermined is dependent on people's experiences with legal authorities (Tyler, 1990).

The theoretical model that we follow is the one which extends the neoclassical utilitarian model of individual violation behavior to include normative and social judgments (Sutinen and Kuperan, 1999; Hatcher and Gordon, 2005), of the form:

$$
V \mathrm{i}=\mathrm{f}\left(\mathrm{Y}_{\mathrm{i}}, \mathrm{D}_{\mathrm{i}}, \mathrm{M}_{\mathrm{i}}, \mathrm{L}_{\mathrm{i}}, \mathrm{S}_{\mathrm{i}} \mathrm{X}\right) \text {, }
$$

where $V i$ is a self-reported violation rate, $\mathrm{Yi}$ is the variable related to the financial incentive to violate, $\mathrm{Di}$ is a vector of deterrence variables such as the probability of detection and the expected fine if detected, $\mathrm{Mi}$ is a vector of variables measuring moral obligation to comply,

$\mathrm{Li}$ is a vector of variables trying to capture perceived regulatory legitimacy; $\mathrm{Si}$ is a vector of social influence variables and $\mathrm{X}$ measure personal characteristics. The hypotheses of interest in this study therefore are:

$$
\frac{\partial \mathrm{Vi}}{\partial \mathrm{Yi}}>0, \frac{\partial \mathrm{Vi}}{\partial \mathrm{Di}}<0, \frac{\partial \mathrm{Vi}}{\partial \mathrm{Mi}}<0, \frac{\partial \mathrm{Vi}}{\partial \mathrm{Li}}<0, \frac{\partial \mathrm{Vi}}{\partial \mathrm{Si}}<0 \text {. }
$$

The main assumption here is that higher measurements of $M_{i}, S_{i}$ and $\mathrm{L}_{\mathrm{i}}$ correspond, respectively, to: stronger moral judgments against violation, perceptions of stronger social norms against violation and increasingly positive judgments concerning legitimacy of regulations and of the regulating authorities. It must be pointed out that we do not have prior predictions of the direction of the $\mathrm{X}$ variables. 


\section{Econometric specification}

The point of departure is that the dependent variable, violation, is a latent variable that describes the degree to which Loggers are in violation of the forest management regulation. The violation is measured in the number of months in which the Loggers violated the forestry regulation. The values therefore range from 0 for non-violators to 12 months for persistent violators. In general we specify our model as:

$$
\mathrm{V}_{\mathrm{i}}=\mathrm{X}_{\mathrm{i}}{ }^{\prime} \beta+\varepsilon \text {, }
$$

where $\mathrm{X}$ is a vector of an observable variable possibly governing $V$ and $\varepsilon$ is normally distributed with mean 0 , and standard deviation $\sigma$. Data on $V$ are only observed when $V=j$ for some $j$ in $(0,1,2)$, where 0 is for non-violators, 1 is for those who violated for one to ten months (occasional violators) and 2 is for those who violated for eleven months or more (persistent violators). We are interested in why loggers may choose to comply rather than violate the rules and vice versa. It is often found that for any regulation there is a small subgroup of persistent violators (Feldman, 1993), a condition which seems also to exist in forestry. Also, those who always obey the rules may on some occasions be attracted to deviate from their normal behavior, but lack the possibility to do so. A simple reason could be that they do not possess the illegal (legal) gear, which implies that the model will fit those who actually alternate between legal and illegal acts. Excluding the others would be a waste of information and lead to biased estimates, as there is self-selected participation. In this study we use the generalized Heckman procedure (Heckman, 1979). In the first step, the probability that a given individual Loggers will violate the forestry regulation is determined from an ordered probit model using all available observations in the three categories. In the second step, the inverse Mills ratio term is used as an instrument variable in the regression on the sub-sample of occasional violators to correct for bias. Using the least square method has the advantage that it allows us to directly interpret the parameter in the selection model as a conditional marginal effect. The ordered probit model is:

$$
\begin{array}{rlll}
\mathrm{V}^{*}=x_{\mathrm{i}}{ }^{\prime} \beta+\mathrm{u}, & & \\
0 \text { if } v * & \leq & \mu 1 \\
V=1 \text { if } \mu 1 & < & \mathrm{v}^{*}<\mu 2 \\
2 \text { if } v * & \geq & \mu 2
\end{array}
$$

where $V^{*}$ is not observed and $V$ is its observed counterpart, $x_{i}$ is a vector of explanatory variables $\mu_{1}$ and $\mu_{2}$ are threshold parameters to be estimated with the $\beta \mathrm{s}$ ', the subscript $\mathrm{i}$ is the index of the individual and the error term $u$ is distributed as standard normal (Greene, 2000).

NOTE: 
$\lambda(x)=\phi(X) /[1-\Phi(X)]$, where $X$ is a vector of regressors related to the violation decision, $\phi$ is the standard normal probability density function, and $\Phi$ is the standard normal cumulative distribution function.

\section{Results}

The descriptive statistics are reported in Table 1. The sample consists of 222 loggers of whom $48 \%$ are non-violators, $46 \%$ are occasional violators and $6 \%$ persistent violators. The overall violation rate is $29 \%$.

Table 1: Descriptive of Variables Included in the Estimations

\begin{tabular}{|c|c|}
\hline Name & Variable description \\
\hline $\mathrm{AGE}$ & Age of the Loggers \\
\hline EDL & Education Level \\
\hline YLELB & Years of Loggers Experience In Log Bussiness \\
\hline LAMIS & Loggings As Main Income Source (1/0) \\
\hline POLDCA & Presence Of Loggers During Cutting Activity (1/0) \\
\hline DFOVU & Dummy For Operational Vehicle Use \\
\hline DFTTF & Dummy For Targeting Thick Forest \\
\hline DFIZ & Dummy For Ife Zone \\
\hline DFILZ & Dummy For Ilesa Zone \\
\hline DFIKZ & Dummy For Ikirun Zone \\
\hline DFOZ & Dummy For Osogbo Zone \\
\hline DFIWZ & Dummy For Iwo Zone \\
\hline DFEZ & Dummy For Ede Zone \\
\hline \multicolumn{2}{|c|}{ Deterrence variables } \\
\hline NTFOSDA & Number of times the loggers have seen the forest officials during activities \\
\hline ECPUM & Expected difference in value of logs between illegal and legal. \\
\hline NOARDPY & Number of arrests during the past year \\
\hline SPROBD & Subjective probability of being detected \\
\hline SPROBAID & Subjective probability of being arrested if detected \\
\hline SPROBTCIA & Subjective probability of being taken to court if arrested \\
\hline SPROBFGIC & Subjective probability of being found guilty in court \\
\hline \multicolumn{2}{|c|}{ Social variables } \\
\hline EOAFMU & Existence of active forest management unit \\
\hline POLPAVR & Percentage of loggers perceived as violating the regulation \\
\hline PATV & Peer attitudes towards violation ( $1=$ wrong; $0=$ not wrong) \\
\hline \multicolumn{2}{|c|}{ Legitimacy variables } \\
\hline LVIEW & Loggers' views are considered in regulation design $(1 / 0)$ \\
\hline GRIIR & Government regulatory imposition is right $(1 / 0)$ \\
\hline IREN & Inconsistency in regulatory enforcement $\quad(1 / 0)$ \\
\hline FOFR & Fairness of the forest regulation \\
\hline FRAWOA & Forest regulations are well-being of all $(1 / 0)$ \\
\hline LSRAWF & Log size regulations are the well-being of few $(1 / 0)$ \\
\hline LSRTEFM & Logs size regulation is not an effective measure $(1 / 0)$ \\
\hline PENALFO & Penalty given to violators 'fits' the offence (1/0) \\
\hline EIYAIA & Enforcement in your forest area is adequate $(1 / 0)$ \\
\hline MVAND & Many of the violators are not detected $(1 / 0)$ \\
\hline
\end{tabular}


The variables which have to do with deterrence include aspects such as the expected gain per unit effort from violating, how often officials have been seen, a dummy for previous arrest, and the respondent's subjective judgment of probability of detection, of arrest, of being taken to court, and of being found guilty. The probabilities are increasing, which is intuitive; those who are more likely to be convicted will more likely be brought through the legal procedures.

The probability of being taken to court is an exception and is lower than that of being arrested. This is the stage where bribes are most likely to occur and it may be that the respondents have adjusted for the use of bribes. If we disregard the effects of bribes, the average perceived overall probability of being detected and punished is $6 \%$, which is substantially larger than the " below 1 percent, and often at or near zero" found in previous measured by a four-digit scale. However, in the final analysis these answers were recorded as dummy variables with levels three and four being one and levels one and two being zero, where one indicates that the fisher agrees with the statement. The correlation between all of the used variables was estimated, but did not exceed 0.54 .

Table 2. Ordered Probit Probality of the Violation Category Model

\begin{tabular}{|lcc|}
\hline Variable & Coefficient & $\mid \mathrm{P}[|\mathrm{Z}|>\mathrm{z}]$ \\
\hline Constant & $-0.508^{* *}$ & 0.014 \\
\hline EDL & 0.029 & 0.012 \\
\hline YLELB & 0.004 & 0.282 \\
\hline POLDCA & $-0.222^{* * *}$ & 0.000 \\
\hline DFOVU & $0.283^{* * *}$ & 0.000 \\
\hline DFTTF & $0.285^{* * *}$ & 0.000 \\
\hline DFIZ & $0.265^{* * *}$ & 0.000 \\
\hline DFILZ & 0.025 & 0.014 \\
\hline DFIKZ & 0.029 & 0.012 \\
\hline DFOZ & 0.066 & 0.012 \\
\hline DFIWZ & $0.123^{* *}$ & 0.017 \\
\hline DFEZ & $0.211^{* * *}$ & 0.002 \\
\hline & & \\
\hline Deterrence variables & & 0.112 \\
\hline NTFOSDA & 0.026 & 0.000 \\
\hline EDIVOBLAI & $0.0034^{* * *}$ & 0.270 \\
\hline SPROBD & 0.0571 & 0.429 \\
\hline SPROBAID & -0.013 & 0.082 \\
\hline SPROBTCI & -0.109 & 0.416 \\
\hline SPROBFGIC & -0.016 & 0.328 \\
\hline Social variables & 0.066 & 0.020 \\
\hline EOAFMU & $0.165^{* *}$ & 0.144 \\
\hline POLPAVR & 0.149 & 0.328 \\
\hline PATV & 0.034 & \\
\hline LAMI & & \\
\hline Legitimacy variables & & \\
\hline & & \\
\hline
\end{tabular}




\begin{tabular}{|lcc|}
\hline LVIEW & -0.086 & 0.082 \\
\hline GRIIR & -0.012 & 0.378 \\
\hline IREN & 0.967 & 0.479 \\
\hline FOFR & $-0.126^{* *}$ & 0.024 \\
\hline FRAWOA & -0.111 & 0.053 \\
\hline LSRAWF & $0.211^{* * *}$ & 0.002 \\
\hline LSRTEFM & -0.084 & 0.073 \\
\hline PENALFO & $-0.155^{* * *}$ & 0.004 \\
\hline EIYAIA & 0.088 & 0.059 \\
\hline MVAND & $0.123^{* *}$ & 0.017 \\
\hline$\mu$ & $0.868^{* * *}$ & 0.000 \\
\hline Number of observations & & 222 \\
\hline Log likelihood function & & -178.19 \\
\hline Prob [chiSqd]>value & & 0.000 \\
\hline
\end{tabular}
$* * *, * *, *$ indicate significance at the $1 \%, 5 \%$ and $10 \%$ levels, respectively.

The results of the first stage ordered Probit Model are presented in Table 2 above. Cut-off points were tested without any major difference in the parameter estimates or the level of significance. A highly significant estimate of indicates that the three categories (in the response are indeed ordered (Liao, 1994 and Håkan and Razack, 2004). In the model, the dependent variable is an ordered rank of violation frequency where non-violation has a rank of zero, one to ten months of violation has a rank of one, and eleven months or more during the last twelve month period receives a rank of two. Many of the variables are statistically significant and significant variables can be found in all of the four variable subgroups, i.e., socioeconomic, deterrence, social and legitimacy variables

Table 3. Marginal Effects of Significant Variables.

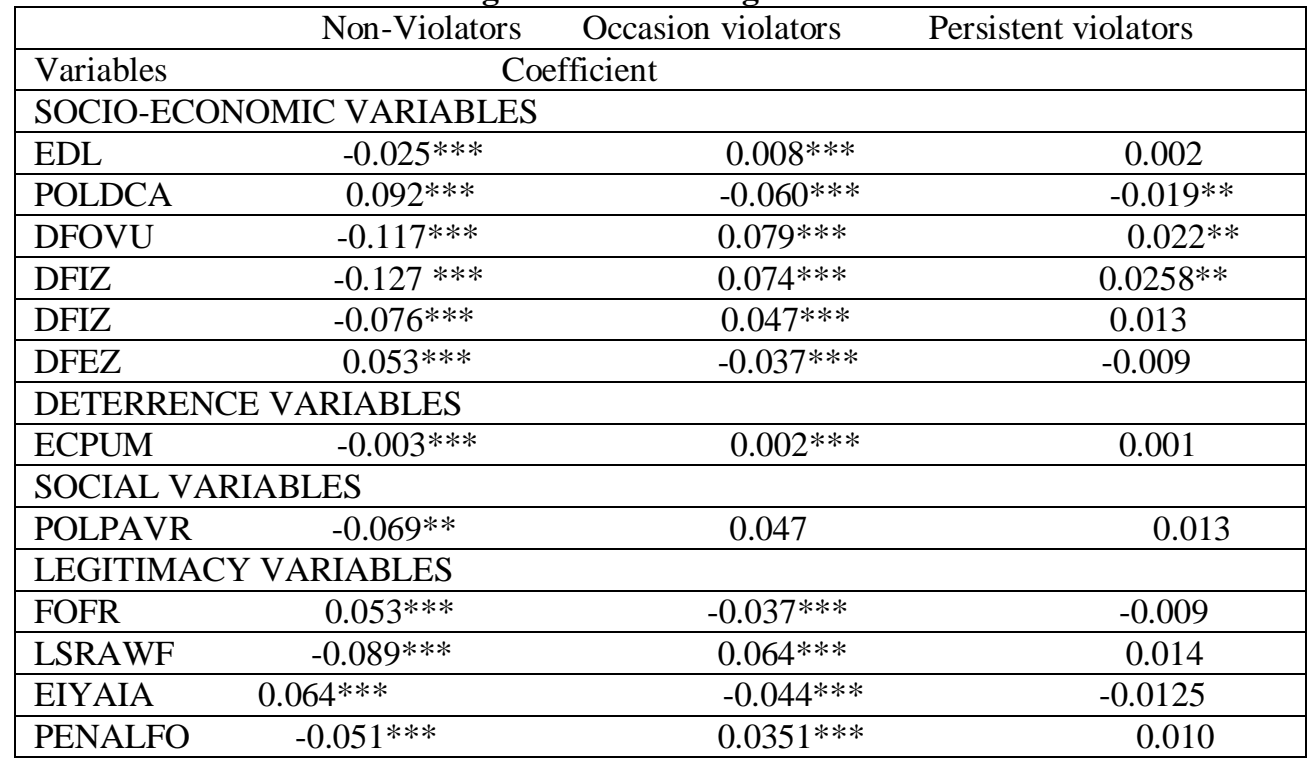


Table 3 depicts the marginal effects for the statistically significant variables, which measure the increased (decreased) probability that the loggers would have been in the violation category, given one more unit of the explanatory variable with the other variables held at their mean. The binary variables, show increase (decrease) in probability if the binary variable is equal to one. For example, the marginal value for non-violation for education is -0.025 (negative), which indicates that the probability for a logger being a non-violator will decrease by $2.08 \%$ for every extra year of schooling he gets. The probability of being in the group of persistent violators is higher if the logger possesses a motor and is from the Ife Zone. Otherwise, explanatory variables are not significant for this group. Whether a logger always obeys the regulations is significantly indicated by a number of variables. More education, being from Ife Zone and possession of a vehicle imply a reduced probability of always obeying the law, while having the owner around during the logging supports non-violation. Among the deterrence variables, only ECPUM is significant, which indicates that if the expected gains between legal and illegal behavior are increasing, then more non-violators are likely to become alternating violators.

Several of the social and legitimacy variables are significant, indicating that these variables have an impact on the decision to be a nonviolator or to consider breaking the rules. The significant variable POLPAVR indicates that the higher the perceived percentage of loggers violating, the lower the probability for the logger to remain a non-violator.

Also, if loggers think that log regulation improves the well-being of a few well established loggers (LSRAWF), they are likely to be alternating violators. If the log size regulation is seen as a fair regulation (FOFR) and the enforcement in their forest area is adequate (EIYAIA), loggers are likely to be non-violators. The penalty (PENALFO) variable has an unexpected significant positive sign for alternating violators, indicating that loggers who believe that the penalty fits the offense are more prone to break the rule. Kuperan and Sutinen (1998) suggest that weak enforcement combined with high social and moral compliance increases the marginal value of violation, which explains why violators are in favor of the measures. The violators enjoy better returns from violating when not all loggers violate due to a suitable penalty. It can be that non-violators think that the penalties are too low while violators think they are low enough to make violation profitable. 
Table 4. Least Squares Estimates of Violation Frequency.

\begin{tabular}{|c|c|c|}
\hline Variable & Coefficient & P-Value \\
\hline Constant & $511 * * *$ & 0.000 \\
\hline \multicolumn{3}{|l|}{ Socio-economic variables } \\
\hline $\mathrm{AGE}$ & -0.002 & 0.089 \\
\hline YLELB & $0.006 * *$ & 0.005 \\
\hline TTF & $-0.232 * * *$ & 0.000 \\
\hline $\mathrm{IZ}$ & 0.025 & 0.190 \\
\hline ILZ & $0.101^{*}$ & 0.084 \\
\hline IKZ & 0.022 & 0.893 \\
\hline $\mathrm{OZ}$ & 0.054 & 0.232 \\
\hline IWZ & 0.061 & 0.702 \\
\hline $\mathrm{EZ}$ & $0.017 * *$ & 0.000 \\
\hline \multicolumn{3}{|l|}{ Deterrence variables } \\
\hline NTFOSDA & $0.070 * * *$ & 0.005 \\
\hline ECPUM & $0.001 * * *$ & 0.006 \\
\hline NOARDPY & $-0.146 * * *$ & 0.002 \\
\hline SPROBD & $-0.070 *$ & 0.030 \\
\hline SPROBAID & $-0.069 *$ & 0.025 \\
\hline SPROBTCIA & 0.028 & 0.170 \\
\hline SPROBFGIC & 0.055 & 0.057 \\
\hline \multicolumn{3}{|l|}{ Social variables } \\
\hline EOAFMU & -0.020 & 0.182 \\
\hline POLPAVR & $0.095 * * *$ & 0.002 \\
\hline PATV & -0.054 & 0.156 \\
\hline \multicolumn{3}{|l|}{ Legitimacy variables } \\
\hline GRIIR & -0.026 & 0.094 \\
\hline LVIEW & $-0.040 *$ & 0.046 \\
\hline IREN & $0.022 *$ & 0.208 \\
\hline FOFR & -0.007 & 0.363 \\
\hline FRAWOA & $-0.046^{*}$ & 0.039 \\
\hline LSRTEFM & 0.012 & 0.274 \\
\hline$\lambda$ (Selectivity correction) & $0.046^{* * *}$ & 0.005 \\
\hline Adjusted R-squared & 0.165 & \\
\hline D-W Statistic & 1111 & \\
\hline Number of Observations & 116 & \\
\hline
\end{tabular}

In table 4 we report the results of the corrected least square estimation of the violation rate.

There is evidence that participation is positively selected as a result of the lambda $(\lambda)$ is positive and statistically significant, which is being adjusted. From the socio-economic variables it can see that loggers from the Ede Zone or with logging experience tend to violate more. Those who target targeting thick forest violate to a lesser extent, which is expected, since targeting thick forest supply the wood processing factories and these factories request a wood 
size corresponding to the legal wood size of large inches. Therefore, if a logger targets thick forest, the market requirements reduce the probability of this logger violating the regulation by 0.23 units compared to the others.

In the case of deterrence variables, it is remarkable that all the four subjective probabilities have the expected negative sign. They are also statistically significant, except for the probability of being taken to court after being arrested (SPROBTCIA). The insignificance of the SPROBTCIA variable may reflect that it is easy to avoid punishment by offering bribes, which is what the logger stated in the interviews. All of the 222 loggers in the sample had experience of being arrested and $19.35 \%$ of them had used bribes to avoid being taken to court. In fact, $23 \%$ of those who had not violated the regulation during the last twelve months had used bribes when being arrested to avoid the problems of being taken to court, even though they were innocent. In the group of persistent violators, $88.58 \%$ avoided being taken to court when arrested by the use of bribes. The difference between illegal and legal logging size values of logging per crewmember effort (ECPUM) is significant in explaining the violation decision.

The NOARDPY variable shows that loggers who have experienced higher arrest rates tend to violate less. The variable NTFOSDA is negative and significant, which indicate that the more often they have seen officials the less likely they are to violate. Social and legitimacy variables depicts that there is influence on the violation rate seems reduced compared to their importance for the decision of whether a logger would be a non-violator or violate the regulation. Those who do, in fact, violate are still influenced by the perceived compliance rate among their colleagues; if they think that many others would violate, then the probability to comply is low. Similarly, they tend to comply if their perception is that loggings' views are considered in the regulation design, and if they believe that the regulation benefits all loggings.

One fundamental issue to address is whether the deterrence or the social and legitimacy variables can be excluded. If we look at the adjusted $\mathrm{R}^{2}$ excluding social, deterrence, and legitimacy, or all three groups of variables, then the full model is reduced from 0.17 to $0.22,0.16$, and 0.11 , respectively. Furthermore, the F-statistics for the various regressions shows that the null hypothesis that all social and legitimacy variables are zero can be rejected at the $5 \%$ level of significance (1.090, critical level 0.91$)$, while zero deterrence variables can be rejected at the $1 \%$ level $(2.518,1.21)$. Therefore, conclusion can be made that both deterrence and social and legitimacy variables are vital in explaining the behavior of the alternating violators.

\section{Conclusion and recommendation}

The basic deterrence model is extended above to allow individual's behavior to be driven by both intrinsic and extrinsic motivations. The 
willingness to comply stemming from moral obligation and social influence is based, inter alia, on the perceived legitimacy of the authorities charged with implementing the regulations. Some evidence suggests that a key determinant of perceived legitimacy is the fairness built into the procedures used to develop and implement policy. To the extent that this is valid, regulatory authorities should determine what policies and practices are judged fair by those segments of the population subject to regulations. This may mean, for example, that civil penalties and other sanctions should be comparable in value to the larger of the harm done or gains realized. This may mean that individuals subject to surveillance and monitoring be treated with dignity and respect. This may mean that regulations must appear reasonable and "make sense."

The result of this work supported by empirical evidence, there are a number of conclusions for policy that flow from the model developed. Perhaps the most important implication is that top-down, command and control-style policies likely will not be perceived as legitimate. The result will be policy that is ineffective in achieving its goals, and a program that is costly and rife with popular dissatisfaction.

Another implication of this result is that policy makers should pay more attention to the fundamental issues of institutional design. Like other political and legal institutions in society, regulatory bodies should devote great effort to developing legitimacy. The mere fact that an institution is formed under a piece of legislation does not necessarily confer on it legitimacy. How legitimacy can be earned is beyond the scope of this short contribution, but is an important issue worthy of future investigation.

More equitable procedures for imposing restrictions on the economic community should strengthen legitimacy and voluntary compliance. Comanagement regimes, in which participants are empowered to play a prominent role in decision making, may be a means of achieving this end (Hanna, 1995). This would address, in part, the need to incorporate procedural justice in the institution. In the absence of incentive programs, the only control mechanism for this subgroup is enforcement. Even if the subgroup of chronic, flagrant violators is small and the amount of their illegal activity is minor, they need to be controlled. Otherwise, flagrant violators would appear to flaunt their violation of the law and to be immune to the regulations. This sends two signals to normally law-abiding participants. One is that regulatory procedures are unfair, having no effect on flagrant violators. The other is that the regulatory program is not effectively achieving its purpose (e.g. protecting the fishery resource). Each of these signals weakens the moral obligation to comply and the moral basis on which social influence is exercised. As moral obligation and social influence are weakened, compliance begins to erode among those who would normally comply with the regulations. 
Similarly, enforcement policies and practices need to be seen by participants to be fair. This may mean (though we do not know) that enforcement authorities should target chronic and flagrant violators of the regulations, punishing them accordingly, while tolerating to some degree minor violations by individuals who normally comply with the regulations.

A collapse of forestry resource, or environmental calamity, can be swiftly and severely dealt with by a legitimate authority, imposing on participants significant short-term sacrifices. Participants who view the authority as legitimate feel a strong obligation to comply even when the dictates of the authority are contrary to their self-interest.

Coercive enforcement measures remain an essential ingredient in any compliance regime, even where a high degree of compliance is realized via the twin forces of moral obligation and social influence. As noted above, in almost any group of individuals subject to regulation there is a core subgroup (usually small) of chronic, flagrant violators motivated largely by the direct tangible consequences of their actions. Moral obligation and social influence have little or no effect on their behavior. Only by changing the economic incentives, by reducing the potential illegal gains or by increasing the expected penalty, can their illegal activity be controlled. Their subsequent noncompliant behavior influences others not to comply with the regulations, and ultimately compliance breaks down. Only effective enforcement can reverse and prevent this undesirable outcome.

\section{References:}

1. Adeyoju, S.K. (2001), Forestry for National Development: A critique of the Nigerian Situation. Forestry and National Development. In the proceedings of the 27th Annual in the proceedings of the conference of Forestry Association of Nigeria management in Nigeria. In sustainable Forest Man-agement in Nigeria: Lesson and prospects. Proceeding, of the 30th Annual conference of the Forestry ueled in Abuja, FCT, 17-21st Sept., 2001. pp55-67. Adeyoju S.K(2005), Institutional arrangements in support of sustainable forest Association of Nigeria held in Kaduna, Kaduna, State, Nigeria 07-11 Nov, 2005. pp 590-598.

2. Affecting Compliance with Fishery Regulations" . Land Economics. 76(3): 448-461.

3. Aina, A. T. and Salau, A. T. (1992). The challenges of sustainable development in Nigeria. Nigerian Environmental Study/Action Team (NEST), Rio-De-Janeiro, Brazil, pp8-16.

4. Ajakaiye, D.O. (2001), Socio-Economic Issues in National Development: Forestry perspective. In forestry and National Development, proceedings of the 27th Annual Conference of FAN 
held in Abuja, FCT, 17-21st Sept., 2001. pp 235 - 245. Amsterdam: North-Holland Publishing Company.

5. Anderson, L.G. and Lee, D.R. (1986), "Optimal governing instruments, operation level, and

6. Areola, O. (1991) Ecology of Natural Resources in Nigeria.

7. Baird M. 2001: Forest crime as a constraint on development. Lecture by country director The World Bank, 13 September 2001, Indonesia. http://wb/n 0018. worldbank org/eap /eap.nsf/Attachment/FLEG-582/\& File/8+2+ Mark + Baird Indonesia, + WB. Pdf.

8. Brack, D., Gray, K; and Hayman, G. (2002), Controlling the International Trade in illegality Logged Timber and wood products. Royal institute of International Affairs (RIIA), London. www.riia.org/pdf/research/sdp/tradeinllegal timber pdf.

9. Colombia' . Journal of Development Economics, 61 (1):1-25.

10. Compliance in Fisheries". Law and Society Review, 32:309-38.

11. Compliance in Fisheries" . Law and Society Review, 32:309-38.

12. Compliance with U.K. Fishing Quotas' Land Economics 81(1):71-86.

13. CTA (1997), Information for rural development the ACP States identify, their priorities, spore, No 67, CTA Wageningen. pp 44 Faleyimu, O. I et al.: Constraints to Forest Policy Implementation in the Southwest Nigeria: Causes, Consequences and Cure

14. Eboh Erick (2005) Harnessing Renewable Resources Sectors for Economic Prosperity. Paper presented at the Economic Workshop Organized by AIEA and Department of International Development Abuja 22nd June 2005.

15. Econ., Vol. 68 No. 3, pp. 678-90.

16. Economics and Trade, 18-21 July, Taipei, Taiwan.enforcement in natural resource regulation: the case of the fishery", Amer. J. Agricultural

17. Erlich, I., (1973) 'Participation in Illegitimate Activities: A Theoretical and Empirical Investigation' Journal of Political Economy 81:3, 521565.

18. Faleyimu O. I and Agbeja B. O (2012): Constraints to Forest Policy Implementation in the Southwest Nigeria: Causes, Consequences and Cure Resources and Environment, 2(2): 37-44

19. FAO. (2001). Global Forest Resources Assessment 2000. Main Report. FAO Forestry

20. FAO. (2005). State of the world's forests. FAO forest report, $153 \mathrm{pp}$.

21. FAO. (2007). State of the World's Forest. Food and Agricultural Organisation of the United

22. Feldman, P. (1993) The Psychology of Crime. New York: Cambridge University Press. 
23. Fiset,N.(2011).Harmful

effects

of deforestation.http.EzineArticles.com/?expert=NathalieFiset

fisheries", paper presented to the 7th Conference of the International Institute of Fisheries

24. FOMECU 1998, Forest Resource Survey, Geomatics, Nigeria Ltd, Abuja.

25. Furlong, W.J. (1991) “ The Deterrence Effect of Regulatory Enforcement in the Fishery".

26. Gaviria, A. (2000) 'Increasing Returns and the Evolution of Violent Crime: The Case of

27. Hatcher, A. and D.V. Gordon (2005) 'Further Investigations into the Factors Affecting

28. Hatcher, A., S. Jaffry., O. Thébaud, and E. Bennett (2000) "Normative and Social Influences

29. Heckman, J.J. (1979)"Sample Selection Bias as a Specification Error" . Econometrica,

30. Heineke, J.M. (Ed.) (1978), Economic Models of Criminal Behavior, North-Holland, Amsterdam and New York.

31. Individual Behavior' In Economic Models of Criminal Behavior, ed. J.M. Heineke.

32. Kuperan, K. and Sutinen, J.G. (1994), "Compliance with zoning regulations in Malaysian

33. Kuperan, K., and J.G. Sutinen (1998), " Blue Water Crime: Legitimacy, Deterrence and

34. Kuperan, K., and J.G. Sutinen (1998), " Blue Water Crime: Legitimacy, Deterrence and Land Economics. 67 (Feb): 116-29

35. Law Review 91:453-99. London

36. Manski, C., (1978) 'Prospect for Inference on Deterrence Through Empirical Analysis of

37. Milliman, S.R. (1986), "Optimal fishery management in the presence of illegal activity”, J. Environ. Econ. and Manage., Vol. 13 No. 4, pp. 363-81.Nations, Rome.

38. Okorie, F.C. (2012). A Spatio-Temporal Analysis of Deforestation in Epe and its Environs (Lagos, Nigeria). Intl. J. Sci., Env., 1(5): 548562.

39. Olagunju, T. E. (2015) Impacts of Human-induced Deforestation, Forest Degradation and Fragmentation on Food Security New York Science Journal 2015;8(1)

40. Richards, M., Del Gatto, F. and Lopez, G.A (2003), The cost of illegal logging in central America how much are the Hondu-ran and Nicaraguan Governments losing? ODI, London www.odi.org.uk/talailegal/eng-evidence.ht. 
41. Robinson, P.H. and J.M. Darley (1997), 'The Utility of Desert', Northwestern University

42. Seyer, J.F 2005, The earth scan Reader in Forestry and De-velopment. Published by Earthscan, London. www. earth-scan.uk. Pp 434.

43. Tyler, T.R., (1990) Why People Obey the Law. Yale University Press, New Haven and Vol.47(1) 153-162.

44. White, A and Martin, A (2002): who own the world's forestry? Forest Tenure and Public Forest in Transition. Forest/Center for International Environmental Law Washington DC.

45. World Bank. (2006). Sustainable Land Management: Challenges, Opportunities and Tradeoffs, Washington, DC. 